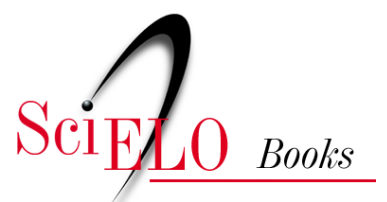

\title{
Capítulo 8 - Perspectivas biotecnológicas para o controle parasitário
}

\author{
Mário Luan Silva de Medeiros \\ Mirna Samara Dié Alves
}

\section{SciELO Books / SciELO Livros / SciELO Libros}

MEDEIROS, M. K. S., and ALVES, M. S. D. Perspectivas biotecnológicas para o controle parasitário. In: BEZERRA, A. C. D. S., and SILVA, M. D. C., eds.

Fitoterapia e a Ovinocaprinocultura: uma associação promissora [online]. Mossoró: EdUFERSA, 2018, pp. 149-160. ISBN: 978-85-57570-91-7. https://doi.org/10.7476/9786587108643.0010.

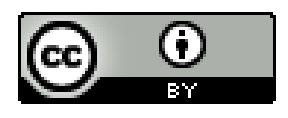

All the contents of this work, except where otherwise noted, is licensed under a Creative Commons Attribution 4.0 International license.

Todo o conteúdo deste trabalho, exceto quando houver ressalva, é publicado sob a licença Creative Commons Atribição 4.0. 


\title{
PERSPECTIVAS BIOTECNOLÓGICAS PARA O CONTROLE PARASITÁRIO
}

\author{
Mário Luan Silva de Medeiros \\ Mirna Samara Dié Alves
}

\section{INTRODUÇÃO}

A Biotecnologia é definida como sendo uma grande área que realiza processos e serviços com a utilização de ferramentas biológicas, os seres vivos e seus constituintes, de forma a proporcionar soluções para problemáticas evidentes na modernidade (ORGANIZAÇÃO, RECONSTRUÇÃO E TRABALHO, 2016). O advento da Biotecnologia colocou em evidência a ampla diversidade de aplicações de suas ferramentas, com o objetivo de alcançar prosperidade e sucesso no desenvolvimento de bens (entre eles, produtos amplamente biotecnológicos) e serviços para distintas áreas do conhecimento.

Nessa perspectiva, evidenciando a grande problemática das doenças parasitárias e a consequente importância dos nematoides gastrintestinais como sendo um fator criterioso no comércio e criação de pequenos ruminantes, a Biotecnologia disponibiliza ferramentas promissoras as quais podem auxiliar no desenvolvimento de novas tecnologias para o controle desses parasitas.

A influência negativa e direta dos helmintos gastrintestinais no setor agropecuário é, sobretudo, agravada pela resistência parasitária. 
A resistência a anti-helmínticos é uma realidade que tem intensificado os danos causados aos pequenos ruminantes, demonstrando a necessidade de desenvolvimento de novas técnicas biotecnológicas que envolvam, preferencialmente, o uso de produtos de origem natural (produtos não sintéticos) para o tratamento animal.

Uma das principais formas de aplicação da Biotecnologia como ferramenta de trabalho nesse horizonte se caracteriza, principalmente, na utilização de estruturas complexas nanométricas. Esse processo se baseia no desenvolvimento de nanopartículas, com a possibilidade de alojar internamente fármacos e com o intuito de atingir exatamente o alvo desejado, ocasionando menor toxicidade e maior eficácia terapêutica (SANTOS, 2016). Em adição, salienta-se também a utilização de técnicas de engenharia genética para o desenvolvimento de vacinas terapêuticas que permitam a imunização e a obtenção de animais resistentes.

Dessa forma, a exploração da Biotecnologia e suas técnicas, nesse campo de pesquisa, propõe de forma promissora o desenvolvimento de variados métodos alternativos para o melhor controle de nematoides gastrintestinais que infectam animais de produção, com a consequente redução no uso dos anti-helmínticos sintéticos e no desenvolvimento da resistência.

\section{NANOBIOTECNOLOGIA PARA O DESENVOLVIMENTO DE CARREADORES DE DROGAS}

Nos últimos anos, pesquisas vêm sendo realizadas com o objetivo de melhorar a biodisponibilidade e ação biológica de diversos químicos sintéticos e dos fitoterápicos, através da associação de ambos os tipos de medicamentos a moléculas carreadoras. A potencialização da atividade terapêutica de fármacos, graças ao encapsulamento, pode levar a uma diminuição no número de administrações do químico 
(KHAN et al., 2015). Essa característica vantajosa colaboraria com a redução do desenvolvimento de resistência anti-helmíntica a um químico sintético específico. O nanoencapsulamento e o uso adequado desses medicamentos podem ser, portanto, uma alternativa viável para o tratamento das helmintoses gastrintestinais de pequenos ruminantes.

A nanobiotecnologia se caracteriza como sendo uma tecnologia a qual trabalha com processos biotecnológicos na formulação de materiais em escala nanométrica. Nesse caso, para a entrega controlada de biomedicamentos. As aplicações associadas com a tecnologia de nanopartículas contendo moléculas químicas biologicamente ativas são novas tendências de abordagens para liberação controlada, entrega em alvo/sítio específico e melhoria da biodisponibilidade do material. Cápsulas de polímeros formuladas em nanoescala têm as vantagens de degradação, liberação do químico com padrão de controle e alta absorção no local específico (KHAN et al., 2015).

Exemplos de materiais utilizados na nanobiotecnologia são os materiais poliméricos sintéticos ou naturais (biopolímeros) que apresentam diversas aplicações biológicas; dentre estas, os polímeros vêm sendo altamente empregados como moléculas carreadoras de fármacos. De maneira geral, os biopolímeros são moléculas biodegradáveis e biocompatíveis, passíveis de utilização em seres vivos.

$\mathrm{Na}$ área de pesquisa em Nanobiotecnologia, os polímeros naturais têm recebido uma atenção especial, por serem produzidos por organismos vivos, apresentando semelhanças químicas, biológicas e estruturais com os seres vivos, sendo, portanto, ainda mais aplicáveis no sentido biológico (FERNANDES, 2009).

Seguindo esse contexto, os polissacarídeos, tais como a quitina e a quitosana, devido às suas propriedades biológicas, têm sido muito aplicados como biomateriais (FERNANDES, 2009). Esses materiais vêm sendo utilizados na forma de micro e/ou nanopartículas e essas, por sua vez, devido às suas habilidades de permeabilidade e proteção 
contra degradação enzimática, têm sido amplamente manipuladas para o carreamento de químicos biologicamente ativos macromoleculares, como proteínas (LUANGTANA-ANAN et al., 2010).

A quitosana, por exemplo, é um polímero linear considerado como um polissacarídeo catiônico, formado por glicosamina e unidades de $\mathrm{N}$-acetil-glicosamina, sendo resultado de uma reação de desacetilação alcalina da quitina (WU; LIN; YAO, 2014). O uso da quitosana como carreador de biomoléculas é favorecido ainda mais pela ausência de toxicidade, pela sua biocompatibilidade, pela sua capacidade de adesão ao muco e sua biodegradabilidade, podendo ser normalmente metabolizada pelos sistemas bioquímicos de seres vivos (LUANGTANAANAN et al., 2010; WU; LIN; YAO, 2014; CERCHIARA et al., 2015).

A utilização de quitosana e outros biomateriais como carreadores de químicos sintéticos ou naturais já é uma realidade que vem demonstrando eficácia e importância no ramo farmacêutico, seja como carreadores de antibióticos (ISLAM et al., 2012; CERCHIARA et al., 2015), de enzimas (WANG; ZHU; ZHOU, 2011) ou outras proteínas (LUANGTANA-ANAN et al., 2010). Portanto, a aplicação dessa tecnologia para o desenvolvimento de fármacos com o emprego de moléculas biodegradáveis pode levar ao aumento de sua biodisponibilidade da droga, melhorando a sua ação biológica. Essa tecnologia é potencialmente aplicável ao desenvolvimento de nanopartículas carreadoras de anti-helmínticos, sintéticos ou naturais, úteis para o controle parasitário mais eficiente.

\section{ENGENHARIA GENÉTICA PARA O DESENVOLVIMENTO DE VACINAS}

A tecnologia do DNA recombinante voltada para a produção de vacinas baseia-se na inserção em um vetor de material genético exógeno de interesse, geralmente associado à expressão de uma proteína cuja 
funcionalidade biológica é conhecidamente ligada a uma doença a qual se deseja prevenir. O vetor irá expressar a informação genética (proteína funcional), produto de uso terapêutico devidamente regulamentado, que servirá para a atuação preventiva no animal vulnerável à patologia (MALAJOVICH, 2012). A comissão Técnica Nacional de Biossegurança, até o ano de 2011, havia aprovado 14 vacinas de uso animal as quais utilizam, na sua formulação, a técnica do DNA recombinante. Porém, há outras pesquisas envolvidas na formulação de vacinas para o uso animal em todo o Brasil (CONSELHO DE INFORMAÇÕES SOBRE BIOTECNOLOGIA, 2016).

Nessa perspectiva, há formulação de vacinas terapêuticas para o uso animal com o propósito de prevenir infecções por nematoides gastrintestinais, sendo as pesquisas nesse campo uma promissora área com o uso da biotecnologia moderna. Esse tipo de vacina é classificado como de terceira geração, as quais utilizam da informação genética do patógeno, no caso dos nematoides gastrintestinais, na busca de possíveis antígenos específicos responsáveis por desencadear uma resposta imune no organismo do hospedeiro, sendo designadas como vacinas de DNA ou vacinas gênicas (MALAJOVICH, 2012). Essas vacinas podem estimular uma resposta imunológica tanto humoral, estimulando a produção de anticorpos específicos para o nematoide, como a resposta imune celular, estimulando os linfócitos $\mathrm{T} \mathrm{CD}^{+}{ }^{+} \mathrm{CD} 8^{+}$; assim, são utilizadas na prevenção da infecção parasitária (SILVEIRA, 2000).

No sistema de produção de vacinas de DNA, há vantagens quanto a sua forma de produção, em termos de maior rendimento, armazenamento com ausência de refrigeração, controle de qualidade simplificado, semelhança entre o antígeno exógeno e a molécula nativa, e o menor custo. Contudo, como desvantagem, há a hipótese de uma possível associação do DNA exógeno com o genoma do hospedeiro, não sendo sabido ao certo o que tais vacinas poderiam desencadear no organismo em longo prazo (SILVEIRA, 2000; MALAJOVICH, 2012). 
Atualmente, há pesquisas sendo norteadas com o objetivo comum da produção de vacinas capazes de imunizar animais suscetíveis às doenças parasitárias (principalmente pelo nematoide Haemonchus contortus - por ser considerado o de maior prevalência dentre os demais, em cerca de $80 \%$ ), de forma eficiente e que não haja retorno da infecção (SANTOS, 2013; YAN et al., 2014).

A produção de vacinas está baseada na descoberta de antígenos diversos, capazes de desencadear respostas preventivas de maior prevalência sobre o organismo. Esses antígenos estão basicamente associados a proteases do tipo aminopeptidades liberadas por células intestinais dos nematódeos, como também a compostos do tipo actina presentes na constituição da membrana das células dos mesmos (BASSETTO et al., 2014a; YAN et al., 2014; ZHOU et al., 2014).

Apesar de todos os esforços para a produção e legalização de uma relevante vacina contra os nematoides gastrintestinais, a maioria das pesquisas ainda está embasadas na produção de vacinas de primeira geração, as quais utilizam antígenos isolados naturalmente dos endoparasitas. Como exemplo, podemos citar as pesquisas (SMITH; ZARLENGA, 2006; BASSETTO et al., 2011; HAN et al., 2012; MOLINA et al., 2012; ROBERTS et al., 2013; BASSETTO et al., 2014a; BASSETTO et al., 2014b; FAWZI et al., 2014; BASSETO; AMARANTE, 2015).

\section{GENÔMICA APLICADA AO CONTROLE PARASITÁRIO}

O padrão de expressão gênica envolvido nas mais diversas etapas do desenvolvimento dos nematoides (ciclo biológico) pode vir a ser útil nas investigações e aplicações biológicas de estratégias de controle desses parasitos, considerando que há diferenciação da expressão gênica durante todo o ciclo do nematoide, desde a fase de ovo até a fase de 
diferenciação do nematoide adulto em macho ou fêmea (LAING et al., 2013; SCHWARZ et al., 2013).

O projeto denominado " 50 Helminth genomes initiative" se propôs a sequenciar nematoides de interesse médico e veterinário. Desses, já foi disponibilizado o acesso do sequenciamento das espécies Echinococcus granulosus, Echinococcus multilocularis, Globodera pallida, Haemonchus contortus, Hymenolepis microstoma, Onchocerca volvulus, Schistosoma mansoni, Strongyloides ratti e Trichuris muris (LAING et al., 2011; SANGER, 2016), dados que podem contribuir para investigações variadas relacionadas ao desenvolvimento de novos métodos de controle parasitário. A espécie $H$. contortus teve o seu genoma sequenciado (Acesso: PRJEB506; NCBI ID: 16936) nesse projeto, sendo o primeiro nematoide estrongilídeo a ser sequenciado, servindo, portanto, como modelo experimental para diversos estudos (JEX et al., 2008; LAING et al., 2013; SCHWARZ et al., 2013; BERLIN et al., 2015).

Esse projeto possui como objetivo central analisar o genoma de nematoides de importância médica e veterinária, de forma a vir a auxiliar biologicamente na descoberta de genes e proteínas que irão fornecer informações preciosas para pesquisas voltadas à busca de alternativas medicamentosas, de vacinas e/ou de marcadores de diagnóstico, no controle desses parasitos (NATIONAL CENTER FOR BIOTECHNOLOGY INFORMATION, 2016a).

Os dados de sequenciamento do genoma de $H$. contortus podem também contribuir com a investigação genética aliada às principais classes de anti-helmínticos sintéticos comercializados, com o intuito de se desvendar a genética da resistência. Nesse sentido, a bioinformática é uma importante ferramenta para o desenvolvimento de estratégias moleculares que busquem o melhoramento farmacológico dos anti-helmínticos ou até mesmo que busquem alvos moleculares alternativos, diferentes dos associados aos dos químicos que apresentam/ 
ocasionam mecanismos de resistência (NATIONAL CENTER FOR BIOTECHNOLOGY INFORMATION, 2016b).

Com as descobertas nas áreas da genômica, transcriptômica e proteômica, esses parasitos vêm sendo cada vez mais utilizados como modelos no desenvolvimento de novos químicos biologicamente ativos, principalmente devido à crescente necessidade de melhor entender os mecanismos genéticos e fisiológicos envolvidos na manutenção da infecção por esses nematoides, bem como os mecanismos genéticos envolvidos no processo de resistência (LAING et al., 2013).

Esse eixo temático encontra-se em crescente desenvolvimento científico, havendo grandes expectativas futuras quanto à realização do controle efetivo dos nematoides de maior prevalência e de maior caráter patogênico aos pequenos ruminantes, existindo uma relação direta entre esse desenvolvimento do conhecimento científico e o surgimento de novas tecnologias aliadas à Biotecnologia. 


\section{REFERÊNCIAS}

BASSETTO, C.C. et al. Protection of calves against Haemonchus placei and Haemonchus contortus after immunization with gut membrane proteins from $H$. contortus. Parasite immunology. v. 33, p. 377-381, 2011.

BASSETTO, C.C. et al . Attempts to vaccinate ewes and their lambs against natural infection with Haemonchus contortus in a tropical environment. International Journal for Parasitology. v. 44, p. 1049 1054, 2014a.

BASSETTO, C.C. et al. Vaccination of grazing calves with antigens from the intestinal membranes of Haemonchus contortus: effects against natural challenge with Haemonchus placei and Haemonchus similis. International Journal for Parasitology. v. 44, p. 697-702, 2014b.

BASSETO, C.C.; AMARANTE, A.F.T. Vaccination of sheep and cattle against haemonchosis. Journal of Helminthology. v. 89, p. 1-9, 2015.

BERLIN, K. et al. Assembling large genomes with single-molecule sequencing and locality-sensitive hashing. Nature Biotechnology, v. 33, n. 6, p. 623-630, 2015.

CERCHIARA, T. et al. Chitosan based micro- and nanoparticles for colon-targeted delivery of vancomycin prepared by alternative processing methods. European Journal of Pharmaceutics and Biopharmaceutics, v. 92, p. 112-119, 2015.

CONSELHO DE INFORMAÇÕES SOBRE BIOTECNOLOGIA. Vacinas. Disponível em: <http://cib.org.br/biotecnologia/saude/ vacinas/>. Acesso em: 26 maio 2016.

FAWZI, E.M. et al. Vaccination of lambs against Haemonchus contortus infection with a somatic protein (Hc23) from adult helminths. International Journal for Parasitology, v. 44, p. 429-436, 2014. 
FERNANDES, L. P. Produção e caracterização de membranas de quitosana e quitosana com condroitina para aplicações biomédicas. 2009, 63f. Trabalho de Conclusão de Curso-Rio de Janeiro: UFRJ, 2009.

HAN, K. et al. Vaccination of goats with glyceraldehyde-3phosphate dehydrogenase DNA vaccine induced partial protection against Haemonchus contortus. Veterinary Immunology and Immunopathology, v. 149, p. 177-185, 2012.

ISLAM, M.A. et al. Design and application of chitosan microspheres as oral and nasal vaccine carriers: an updated review. International Journal of Nanomedicine, v. 7, p. 6077-6093, 2012.

KHAN, I.; KHAN, M.; UMAR, M. N.; O, D-H. Nanobiotechnology and its applications in drug delivery system: a review. The Institution of Engineering and Technology: Nanobiotechnology, v. 9, p. 1-5, 2015.

JEX, A.R. et al. Using 454 technology for long-PCR based sequencing of the complete mitochondrial genome from single Haemonchus contortus (Nematoda). BMC Genomics, v. 9, p. 11, 2008.

LAING, R. et al. Annotation of two large contiguous regions from the Haemonchus contortus genome using RNA seq and comparative analysis with Caenorhabditis elegans. PLoS ONE, v. 6, p. 1-13, 2011.

LAING, R. et al. The genome and transcriptome of Haemonchus contortus, a key model parasite for drug and vaccine discovery.

Genome Biology, v. 14, 2013.

LUANGTANA-ANAN, M. et al. Polyethylene glycol on stability of chitosan microparticulate carrier for protein. American Association of Pharmaceutical Scientists PharmSciTech, v. 11, p. 1376-1382, 2010.

MALAJOVICH, M.A. Biotecnologia 2011. Rio de Janeiro: Edições da Biblioteca Max Feffer do Instituto de Tecnologia ORT, 2012, 320p.

MOLINA, J.M. et al. Immunoprotective effect of cysteine proteinase fractions from two Haemonchus contortus strains adapted to sheep and goats. Veterinary Parasitology, v. 188, p. 53-59, 2012. 
NATIONAL CENTER FOR BIOTECHNOLOGY INFORMATION. Haemonchus contortus Genome sequencing (barber pole worm).

Disponível em: <http://www.ncbi.nlm.nih.gov/bioproject/

PRJEB506>. Acesso em: 12 abr. 2016 a.

NATIONAL CENTER FOR BIOTECHNOLOGY INFORMATION.

Genetics of drug resistance and a linkage map in Haemonchus contortus. Disponível em: <http://www.ncbi.nlm.nih.gov/ bioproject/277152>. Acesso em: 31 maio 2016b.

ORGANIZAÇÃO, RECONSTRUÇÃO E TRABALHO. O que é Biotecnologia? 2011. Disponível em: <http://www.ort.org.br/ biotecnologia/o-que-e-biotecnologia>. Acesso em: 26 maio 2016.

ROBERTS, B. et al. Novel expression of Haemonchus contortus vaccine candidate aminopeptidase $\mathrm{H} 11$ using the free-living nematode Caenorhabditis elegans. Veterinary Research, v. 44, p. 2-15, 2013.

SANGER. Helminth genomes - data download. Disponível em: $<$ http://www.sanger.ac.uk/resources/downloads/helminths/>. Acesso em: 31 maio 2016.

SANTOS, M.L. Polimorfismos responsáveis pela resistência a benzimidazóis em populações de Haemonchus contortus isoladas no estado do Ceará. 2013. 62 f. Dissertação (Mestrado em Ciências Veterinárias), Faculdade de Veterinária, Universidade Estadual do Ceará - UECE, Fortaleza - CE, 2013.

SANTOS, T.T. Medicamentos e nanotecnologia: uma combinação de sucesso. Disponível em: <https://cemedmg.wordpress. com/2012/12/05/medicamentos-e-nanotecnologia-umacombinacao-de-sucesso/>. Acesso em: 14 maio 2016.

SILVEIRA, E. Terapia Gênica. Biotecnologia, Ciência e Desenvolvimento. ano 3, n. 14, 2000.

SMITH, W.D.; ZARLENGA, D.S. Developments and hurdles in generating vaccines for controlling helminth parasites of grazing ruminants. Veterinary Parasitology, v. 136, p. 347-359, 2006. 
SCHWARZ, E.M. et al. The genome and developmental transcriptome of the strongylid nematode Haemonchus contortus. Genome Biology, v. 14, 2013.

WANG, X.; ZHU, K.X.; ZHOU, H.M. Immobilization of glucose oxidase in alginate-chitosan microcapsules. International Journal of Molecular Sciences, v. 12, p. 3042-3054, 2011.

WU, Q.X.; LIN, D.Q.; YAO, S.J. Design of chitosan and its water soluble derivatives-based drug carriers with polyelectrolyte complexes. Marine Drugs, v. 12, p. 6236-6253, 2014.

YAN, R. et al. DNA Vaccine encoding Haemonchus contortus actin induces partial protection in goats. Acta Parasitologica, v.59, p. 698-709, 2014.

ZHOU, Q.J. et al. Expression of Caenorhabditis elegans expressed Trans-HPS, partial aminopeptidase H11 from Haemonchus contortus. Experimental Parasitology, v. 145, p. 87-98, 2014. 